\title{
Hurricane Sandy and adaptation pathways in New York: Lessons from a first-responder city
}

\author{
Cynthia Rosenzweig ${ }^{\mathrm{a}, \mathrm{c}, *}$, William Solecki ${ }^{\mathrm{b}}$ \\ a NASA Goddard Institute of Space Studies, 2880 Broadway, New York, NY 10025, USA \\ ${ }^{\mathrm{b}}$ CUNY Institute for Sustainable Cities and Department of Geography, Hunter College - City of New York, 695 Park Avenue, New York, NY 10021, USA \\ ${ }^{c}$ Columbia University Center for Climate Systems Research, 2880 Broadway, New York, NY 10025, USA
}

\section{A R T I C L E I N F O}

\section{Article history:}

Received 16 September 2013

Received in revised form 29 April 2014

Accepted 4 May 2014

Available online 3 July 2014

\section{Keywords:}

Adaptation pathways

Cities

Climate change

Resilience

Transformation

\begin{abstract}
A B S T R A C T
Two central issues of climate change have become increasingly evident: Climate change will significantly affect cities; and rapid global urbanization will increase dramatically the number of individuals, amount of critical infrastructure, and means of economic production that are exposed and vulnerable to dynamic climate risks. Simultaneously, cities in many settings have begun to emerge as early adopters of climate change action strategies including greenhouse gas mitigation and adaptation. The objective of this paper is to examine and analyze how officials of one city - the City of New York have integrated a flexible adaptation pathways approach into the municipality's climate action strategy. This approach has been connected with the City's ongoing response to Hurricane Sandy, which struck in the October 2012 and resulted in damages worth more than US\$19 billion. A case study narrative methodology utilizing the Wise et al. conceptual framework (see this volume) is used to evaluate the effectiveness of the flexible adaptation pathways approach in New York City. The paper finds that Hurricane Sandy serves as a "tipping point" leading to transformative adaptation due to the explicit inclusion of increasing climate change risks in the rebuilding effort. The potential for transferability of the approach to cities varying in size and development stage is discussed, with elements useful across cities including the overall concept of flexible adaptation pathways, the inclusion of the full metropolitan region in the planning process, and the co-generation of climate-risk information by stakeholders and scientists.
\end{abstract}

Published by Elsevier Ltd.

\section{Introduction}

Hurricane Sandy struck the East Coast of the United States on October 29, 2012 and brought the issue of urban resilience to the forefront of public discussion not only in New York City, but in cities around the world. Globally, climate change is already increasing the frequency and intensity of some extreme events, such as heatwaves and heavy downpours, and these effects are projected to accelerate in the future (IPCC, 2013). Highly germane to coastal cities, flooding events from storms are expected to increase in frequency and extent due to sea level rise (IPCC, 2013). While Hurricane Sandy as an individual extreme climate event cannot be attributed to climate change, it serves as warning for cities regarding disaster risks, focuses attention on the importance of reducing climate vulnerability, and highlights the need to

\footnotetext{
* Corresponding author. Tel.: +1 212678 5562; fax: +1 2126785648 .

E-mail addresses: crr2@columbia.edu (C. Rosenzweig), wsolecki@hunter.cuny.edu (W. Solecki).
}

include increasing climate risks and resilience into rebuilding programs.

Hurricane Sandy motivates an examination of how New York City had been addressing climate risks before and after the storm, specifically through an analysis of the flexible adaptation/ resilience approach developed by the City in the years prior to its occurrence. This paper is one of the first critical evaluations of how New York City has embraced adaptation pathways, with special attention to the major decision point propelled by Hurricane Sandy (see also Wagner et al., 2014). It then expands the analysis to the use of adaptation pathways in other cities, examining whether this concept is easily transferable to a variety of urban settings.

The work in New York City is situated at the nexus of climate change adaptation (CCA) and disaster risk reduction (DRR). Solecki et al. (2011) focus on the overlaps between CCA and DRR in cities in regard to event likelihoods related to hazards, risks and uncertainty; key impact parameters of exposure, vulnerability, and equity; and societal responses related to adaptive capacity and resilience. The linkages between DRR and CCA strategies in New 
York and other cities have started to change how researchers and practitioners conceive and approach the analysis and management of urban climate risks and associated impacts and response activities.

Further, this work is embedded in the context of current thinking on the potential for transformational adaptation when incremental adaptations to climate change prove insufficient (e.g., Folke et al., 2010; Kates et al., 2012). Folke et al. (2010) laid out definitions and issues relating to the integration of resilience, adaptability, and transformability across multiple scales. Resilience is the capacity of a social-ecological system (SES) to continually change and adapt yet remain within critical thresholds. Adaptability is part of resilience and represents the capacity to adjust responses to changing external drivers and internal processes and thereby allow for development along the current trajectory. Transformability is the capacity to cross thresholds into new development trajectories.

The key issue following Hurricane Sandy is whether it represents a tipping point that leads to new development trajectories, i.e., toward transformative adaptation (Kates et al., 2012). While challenges to transformative adaptation relate to the high costs of such actions, and the inertia that tends to maintain existing policies and systems, crises can provide windows of opportunity for innovation. Thus we explore whether Hurricane Sandy, as such a focusing event, has helped to initiate transformative adaptation in the New York Metropolitan Region.

\section{Flexible adaptations pathways in New York City}

In 2008, Mayor Bloomberg convened the First New York City Panel on Climate Change (NPCC, 2010). NPCC1, which was composed of leading climate and social scientists and risk management experts, developed climate change projections, advised on adaptation assessment, and examined how standards and regulations could be revised. The New York City Panel on Climate Change projects with high confidence that there will be increased heatwaves, heavy rainfall events, and extended coastal flooding in the New York metropolitan region in the coming decades (NPCC, 2010, 2013) (see Supplementary data Table 1 and Table 2).

To manage these increasing risks, the NPCC1 in conjunction with city stakeholders developed the flexible adaptation pathways' approach to guide the City in developing greater resilience (NPCC, 2010). The key elements of the approach are the explicit recognition that risk management strategies need to evolve through time in response to continuous climate risk assessment, evaluation of adaptation strategies, and monitoring. New York City climate resilience plans were included in the 2011 update of PlaNYC, the long-term sustainability plan for New York City, and set forth eleven initiatives that spanned continuing vulnerability and risk assessments, as well as updating building regulations, and improving responses to extreme events (NYC, 2011).

The concept of 'flexible adaptation pathways' as an approach to responding to climate change was laid out by the New York City Panel on Climate Change in 2010 (Yohe and Leichenko, 2010; NPCC, 2010; Major and O'Grady, 2010). The NPCC1 application of the concept as a planning tool is based on the study done by the City of London and the UK Environment Agency for the renovation of the Thames barriers (Lowe et al., 2008; Reeder and Ranger, 2011; Ranger et al., 2013). The New York City flexible adaptation framework encompasses both mitigation and adaptation and enables the consideration of long-range goals as well as their translation into short-term objectives.

The NPCC flexible adaptation pathways conceptual framework shown in Fig. 1a represents the societal 'acceptable level of risk' (wavy horizontal line), as fluctuating rather than static. For example, the acceptable risk level of New York inhabitants has without doubt been lowered by the experience of Hurricane Sandy. The schematic indicates that without climate change mitigation or adaptation, the acceptable level of risk could be crossed relatively soon. Inflexible adaptation standards, even with mitigation, improves the status quo but eventually results in crossing the acceptable risk level. Flexible adaptation consists of a successive set of strategies developed and implemented as knowledge and understanding of climate change proceeds. However, without greenhouse gas emission mitigation actions, adaptation by itself might not be enough to maintain (within socially defined cost limits) the urban system at an acceptable level of risk on the multidecadal timeframe. Thus, the combination of flexible adaptation strategies with mitigation (with the caveat that mitigation must occur on both local and global scales to be effective) will enable New York City to remain below the acceptable level of risk as climate change proceeds.

The NPCC emphasized that flexible adaptation pathways are not fixed; adaptations are defined in terms of acceptable risk levels and are re-evaluated over time, rather than using an approach that sets inflexible standards for adaptation early in the process (NPCC, 2010). More permanent, inflexible approaches (e.g., sole reliance on large-scale storm surge barriers) are likely to be costlier and less effective in the long term than flexible adaptation pathways in implementing adaptations to dynamic and on going climate change conditions. In recognition of the City's need for climate risk information through time, the City Council of New York City codified the NPCC in August 2012 legislation, signed by Mayor Bloomberg in September, requiring the establishment of the NPCC as an body to provide regular climate science updates and localized projections. This was set in place 2 months before Hurricane Sandy and helped to formalize the flexible adaptation pathway approach within the City's response strategy.

Fig. 1b presents the specific timeline and trajectory of NYC's flexible adaptation pathways, key milestones and decision points, and adaptation actions. The blue line in Fig. $1 \mathrm{~b}$ represents the socially acceptable level of risk that was rising gradually over time before Hurricane Sandy. The spike in the yellow line (the trajectory of NYC's flexible adaptation pathway) shows that the socially acceptable risk level was breached during Hurricane Sandy. Immediately following Sandy, multiple measures designed to bring the flexible adaptation pathway below the socially acceptable level of risk were rapidly adopted.

\section{Hurricane Sandy}

Hurricane Sandy hit New York City on the evening of October 29, 2012 (NPCC, 2013). Some weather prediction models provided accurate forecasts of the storm track and intensity of a MidAtlantic landfall more than one week in advance. As a measure of the storm's strength, Sandy had a central pressure of $945 \mathrm{mb}$, the lowest on record at landfall of any storm north of North Carolina. Sandy's wind field extended about $1610 \mathrm{~km}$ (1000 mil.). The peak storm surge of $2.9 \mathrm{~m}(9.4 \mathrm{ft})$ coincided closely with high tide in the areas facing the Atlantic Ocean, especially in Staten Island and Brooklyn. The storm tide at The Battery at southern Manhattan, just meters away from the Wall Street financial center, was $4.3 \mathrm{~m}$ (14.1 ft) above mean lower low water (MLLW), or $3.4 \mathrm{~m}(11.3 \mathrm{ft})$ above the North American Vertical Datum (NAVD88) (Blake et al., 2013).

Hurricane Sandy flooded the area roughly equivalent to that projected by NPCC 1 for the 1 -in-100 year storm 'rapid ice-melt' sea level rise scenario in the 2080s (Fig. 2). The NPCC1 'Rapid ice-melt scenario' was based on acceleration of recent rates of ice melt in the Greenland and West Antarctica ice sheets and paleoclimate studies (Horton et al., 2010). Two elements contribute to this surprising 
a)

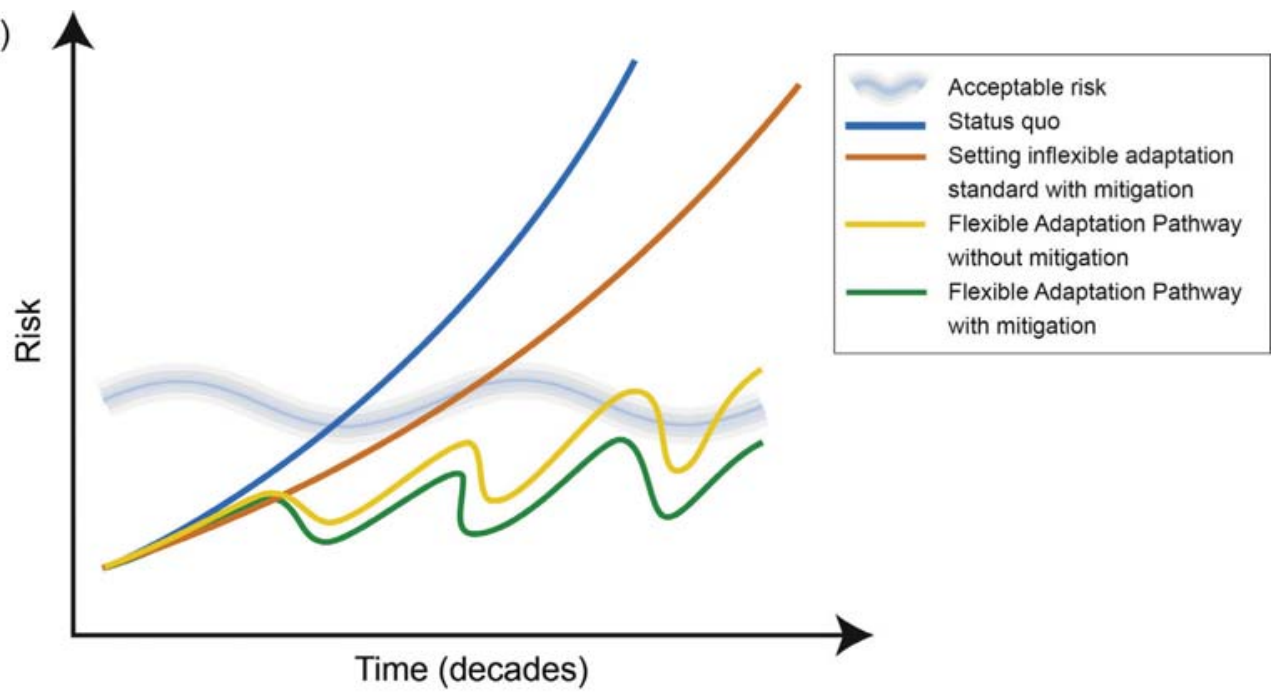

Time (decades)

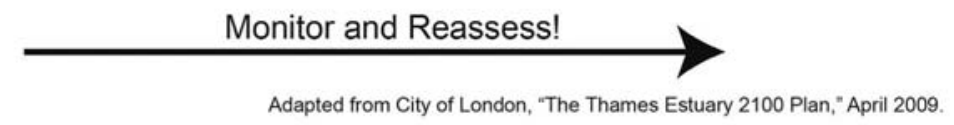

b)

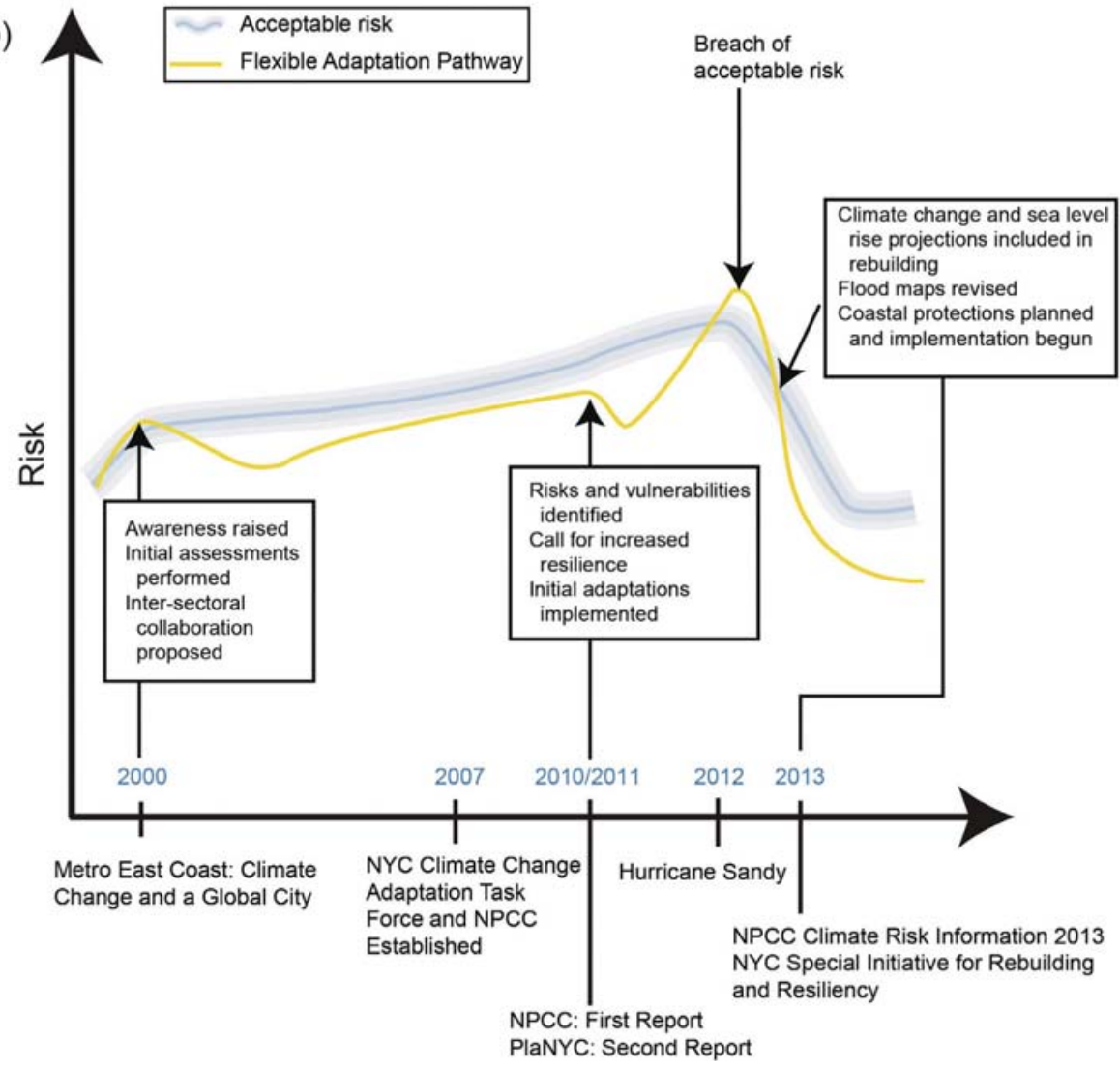

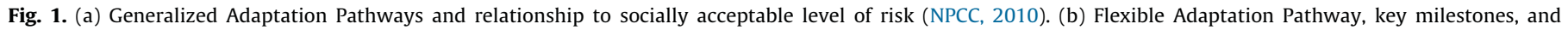
relationship to socially acceptable level of risk in the New York metropolitan region, 2000-2014. (Rosenzweig and Solecki, 2001; NPCC, 2013; SIRR, 2013).

result: (1) Hurricane Sandy was a greater than a 1-in-100 year occurrence; indeed it was an exceedingly rare, one-in-multi-century event; and (2) the FEMA 1983 flood levels that were used as the baseline for the NPCC1 projections (used at the request of New York City so as to be relevant for then-current insurance programs) underestimated the current risk level. The NPCC1 map in Fig. 2a captured the correct area that could potentially flood during highmagnitude events, but was not accurate in regard to timing.
Depending on the storm characteristic considered, Hurricane Sandy was a 714-year event for its impact angle at New Jersey landfall (Hall and Sobel, 2013); a 500-year event for its storm surge at the Battery in Manhattan (Aerts et al., 2013); and a 1000-year event (McCulloch, 2013). The FEMA 1983 1-in-100 year NYC floodplain has since been drastically revised from $85 \mathrm{~km}^{2}\left(33 \mathrm{mi}^{2}\right)$ to $124 \mathrm{~km}^{2}$ ( $\left.48 \mathrm{mi}^{2}\right)$, representing a $45 \%$ increase and a much greater area at risk (FEMA, 2013; SIRR, 2013). The number of New 

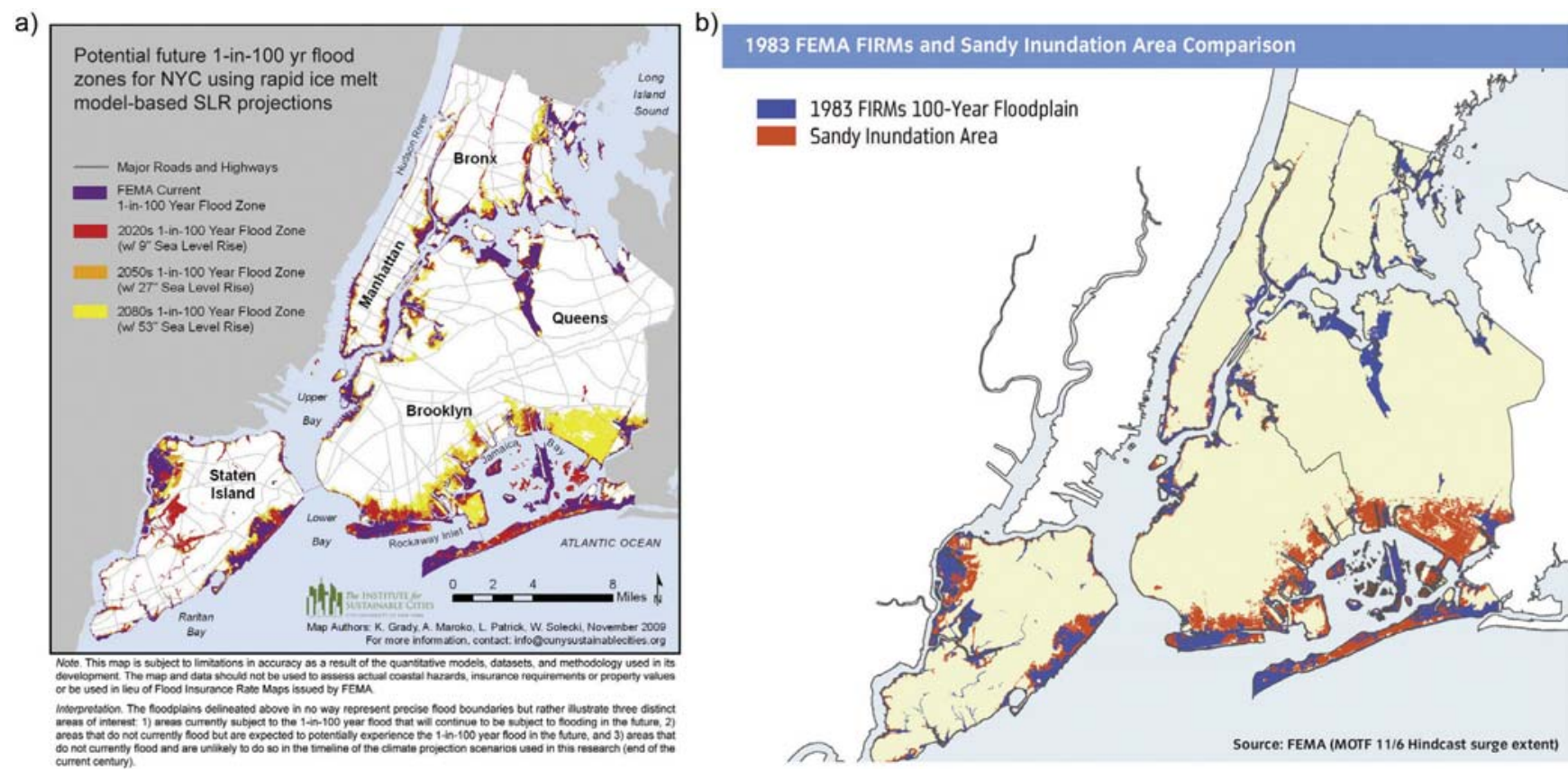

Fig. 2. (a) Potential future 1-in-100 year flood zones for NYC using rapid ice melt model-based sea level rise projections (NPCC, 2010). (b) Areas flooded by Hurricane Sandy compared to the FEMA 1983 Flood Insurance Rate Map (FIRM) 100-Year floodplain (New York City, 2013).

Yorkers living in the 100-year floodplain went from about 218,000 to almost 400,000 (an increase of 83\%) (SIRR, 2013).

The impacts of Hurricane Sandy were severe and extensive. The mandated evacuation of the New York City Evacuation Zone 1 was not complete, and impacts were especially significant in Manhattan, Staten Island, Brooklyn, and Queens (Fig. 3). Forty-three people died in the City, $80 \%$ from drowning, with other deaths attributed to falling trees and electrocution. The utilities were not prepared, with extensive electricity power outages leaving close to 2 million people without power in New York City (SIRR, 2013), some for several weeks, and management of repair crews a challenge. The Metropolitan Transit Authority and the Department of Transportation experienced major flooding, with seven subway lines and three vehicular tunnels closed under the East River.

In coastal areas of the city such as the Far Rockaways, Queens, there was widespread beach erosion, flooding, and boardwalk damage. Estimated losses due to Hurricane Sandy in New York City are about \$19 billion USD (SIRR, 2013).

Impacts that were not foreseen included widespread gas shortages, several major hospital evacuations, and fires caused by gas line breaks in coastal neighborhoods. Damages and losses were exacerbated by the inability of fire crews to navigate narrow or flooded streets.

As we look back at Hurricane Sandy, key questions are: How well did preparations work? What worked better than expected, what less well? and Why was the destruction so great? The forecast for Hurricane Sandy's storm track proved to be accurate, with the European Centre for Medium-Range Weather Forecasts (ECMWF) providing the track accurately more than a week in advance (Hewson, 2012). This gave adequate time for a set of immediate preparations to be instigated. Successful nearterm preparations included the warnings, advisories, and evacuation orders issued (the latter on October 28, 2012); the system-wide shutdown of the Metropolitan Transit Authority subways, buses, rail lines, ferries, tunnels, bridges, and highways; the moving of the rolling stock of the train systems to higher ground (this is in contrast to New Jersey Transit that did not and that suffered severe damage as a result). By the end of October 29, the Lincoln Tunnel was the only Manhattan tunnel entry point that remained open (Note: Numerous bridges remained operational.)

Despite the effectiveness of these preparations, there are a multitude of reasons that the destruction caused by Hurricane Sandy was so great. Here it useful to utilize the overlapping rubric of hazards, exposure/sensitivity, and adaptive capacity (Rosenzweig et al., 2011c). On the hazard side, the storm was a rare, highmagnitude event that hit at high tide in New York Harbor and along the Atlantic Ocean. Its strong winds amplified waves and storm surge, downed trees causing widespread power outages, and weaked widespread damage via flying debris.

In regard to exposure, both exposure and sensitivity were high. When Sandy hit, 35,700 structures, comprised of 162,700 residences, were situated in high-risk flood areas (Dixon et al., 2013). Eighty percent of these were built prior to 1983 (the time of the last FEMA flood mapping exercise). Only about 55\% of the residences had federal flood insurance before Sandy. Staten Island, the hardest hit borough, was the site of the highest percentage of people living within a floodplain. Roughly $16 \%$ of Staten Island was inundated, affecting more than 75,000 people.

Other factors that contributed to the high exposure were the progressive loss of coastal wetlands through centuries of development, the prevalence of older buildings and infrastructure, and the outdated FEMA flood maps that provided an incomplete portrayal of actual risk levels.

In regard to adaptive capacity, efforts had been made to prepare for high-risk coastal flooding events through a variety of City agencies, but they had not been made at the required scale. Adaptive measures taken before the storm included beach nourishment in Coney Island and Brighton Beach, dune restoration at Rockaway Peninsula, elevated structures at Battery Park City, and some constructed wetlands with elevated edges (e.g., Alley Creek in Queens). Bulkheads were largely washed over by the storm surge, but did diminish wave energy in Bay Ridge and Lower Manhattan. However, even taken together, these measures were simply not enough to prevent the massive damage caused by the storm.

In the immediate term, acceptance of the advisories and evacuation orders by the general public was hampered by poor 

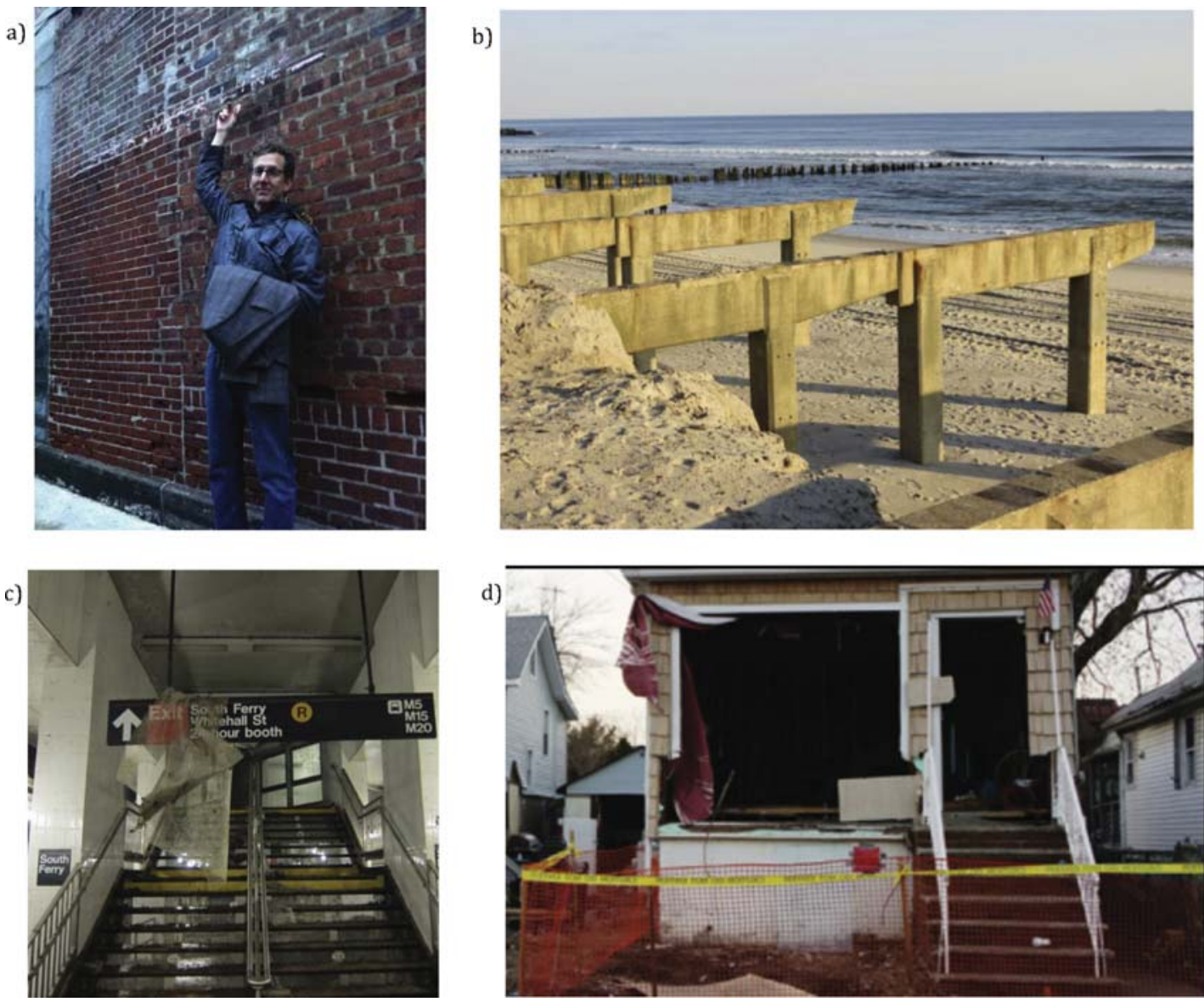

Fig. 3. Impacts of Hurricane Sandy in New York City: (a) High water mark at South Street Seaport, Manhattan (Phillip Orton, Stevens Institute of Technology). (b) Concrete support beams at the boardwalk destroyed in Rockaway Park, Queens (Gary Monitz, Columbia University). (c) Damage at South Ferry subway station in Manhattan (Daniel Bader, Columbia University). (d) Damaged home in Staten Island (Somayya Ali, Columbia University).

communication and lack of appropriateness in advisories, for instance to non-English speaking inhabitants and those living in high-rise apartment buildings. Baker et al. (2012) surveyed residents and found that they underestimated the strength of the storm.

However, while any loss of life is unacceptable, these preparations contributed to the relatively low numbers of fatalities (43 in New York City compared with 853 in New Orleans during Hurricane Katrina, although storms and storm impacts are difficult to compare across locations) (Boyd, 2011).

In regard to the longer term, however, the City and the Metropolitan Transit Authority had not fully incorporated climate risks into major infrastructure projects, such as the $\$ 530$ million renovation of the South Ferry Station, near the Battery in southern Manhattan, started in 2005 and completed in 2009. The station was built in the flood zone without waterproofing and flood protection and suffered extensive damage during Hurricane Sandy. The new South Ferry Subway Station is not scheduled to re-open for about three years (the old South Ferry station was reopened in April 2013 to function in the interim).

The experience of Hurricane Sandy leads to the need to understand whether the storm risk assessment was flawed, whether New York City had poor standards of risk management, or whether New Yorkers had a very low risk aversion. We believe that while the storm risk assessment process worked reasonably well in the week before the storm's occurrence, the linked factors of low risk aversion and low levels of coastal risk management contributed to the magnitude of the damages. For example, there was overall low ownership of flood insurance policies; furthermore, many thought that their policies included flood damage but they did not. Kunreuther (2008) emphasizes that lack of investment in protective measures from rare events is due to concerns over low returns over a short time period - the time horizon used by most residents. This temporal disconnect with the flooding hazard is counter-productive to effective coastal risk management.

Prior to Hurricane Sandy, New York City did play an important leadership role in setting up an effective process for determining climate risks and focusing attention on climate change adaptation (NPCC, 2010; PlaNYC, 2011). In the early phase [from 2008 when the NPCC and the Climate Change Adaptation Task Force (CCATF) were convened until Hurricane Sandy in 2012] efforts focused on risk management of critical infrastructure. The work of the CCATF culminated in a set of resilience initiatives related to built and natural environments, public health, and preparedness for extreme climate events presented in the 2011 PlaNYC Annual Report (PlaNYC, 2011), which did contribute to damage reduction during the storm.

\section{The tipping point}

Hurricane Sandy was a major decision point in adaptation policy in New York City. Following the storm, Mayor Bloomberg explicitly brought climate change into response planning. In December 2012, Mayor Bloomberg established the citywide Special Initiative for Rebuilding and Resiliency (SIRR) and convened the second New York City Panel on Climate Change (NPCC2). The 2013 NPCC2 Climate Risk Information (CRI) Report provided updated climate change projections utilizing state-ofthe-art modeling tools (i.e., CMIP5) and new future coastal flood 
risk maps for New York City. CMIP5 is the Coupled Model Intercomparison Project Phase 5. CMIP provides a framework for standard protocols and comparison in global climate modeling, and the outputs are used in the IPCC assessments (see Taylor et al., 2012). The NPCC advised the City of New York to use CMIP5, the latest phase, for the city's climate projections to ensure the most up-to-date scientific assessment possible. Both the SIRR and CRI reports were released in June 2013 (SIRR, 2013; NPCC, 2013).

The goal of the SIRR is to protect New York's infrastructure, buildings, and highly-exposed communities from the impacts of storm surge and long-term climate change-related sea level rise. The SIRR focused largely on small-to-medium scale flood protection strategies with a range of green infrastructure (e.g., wetland restoration to attenuate wave action) and regulatory approaches (e.g., standards and codes). Fundamentally, the Report defined an overall policy of "no-retreat" from the coast.

The SIRR report provides detailed plans for the use of the rebuilding funds appropriated by the US Congress in December 2012 and January 2013 in response to Hurricane Sandy. Of the approximately $\$ 15$ billion worth of adaptation actions detailed in the SIRR, approximately $\$ 10$ billion was supposed to come from US Congressional appropriations, with about $\$ 5$ billion coming from City funds and other sources, with the source of the remaining funding yet to be identified (SIRR, 2013). The plan encompasses a wide range of adaptive measures.

The hardest-hit and most vulnerable neighborhoods will be protected by off-shore breakwaters or wetlands, and more sandnourished beaches and dunes will shield inland communities (SIRR, 2013). In other areas, floodwalls will hold back rising seas, and raised and reinforced bulkheads and tide gates will protect against storm surge. Homes will be hardened and in some cases elevated. Expanded green infrastructure, including dunes and wetlands, will play an important role.

The SIRR also addressed the need for improved insurance programs to deal with increased risks of coastal flooding due to climate change. These included targeting affordable insurance for low-income policy-holders, defining resiliency standards for existing buildings, expanding pricing opinions of policy-holders, and improving awareness and education about insurance (SIRR, 2013). Scaling-up plans and investments in New York City following Hurricane Sandy is occurring in the larger context of rethinking coastal flood insurance in the U.S. (Michel-Kerjan and Kunreuther, 2011). Adaptation measures can significantly reduce losses and premiums and extend the amount of coverage that could be provided by the private insurance market. Use of loss reduction measures and provision of reinsurance to counter catastrophic losses can increase the availability of insurance and make it more affordable to people even under high-loss climate change scenarios. Not only does adaptation significantly reduce the estimated losses associated with a given climate change scenario, it can also substantially reduce the uncertainty in the price of insurance.

At the time of the writing of this article, the government of New York City is implementing initial elements of the SIRR plans in compliance with the funding requirements of the federal government. Can investment levels be expected to be maintained? Past experience shows that they often are not due a combination of behavioral, political, and economic issues. Postdisaster responses are often to 'forget and move on,' while politically, administrations find it difficult to maintain momentum and funding for disaster preparedness as a top priority. This must be overcome if adaptive transformation is truly to take hold.

\section{Evaluating the NYC flexible adaptation pathways approach}

Multiple dynamic approaches to adaptation planning under uncertainty have been proposed in the literature (e.g., Haasnoot et al., 2012; Hallegatte, 2009; Ranger et al., 2010). The flexible adaptation approach taken up by New York City combines two major concepts: resilience and dynamic robustness (see Walker et al., 2013 for review of relevant definitions). The goal of the City is to develop climate adaptation plans that ensure that whatever climate hazard or combination of hazards that occurs, the critical infrastructure systems of the City would be able to recover from the impacts. The NYC resiliency approach accepts that there will short-term productivity losses, but focuses on recovery.

The NYC approach also embraces dynamic robustness, i.e., the City is developing plans that can be changed over time as more is learnt or as conditions change. The focus is on short-term actions that reduce risk iteratively, while laying a framework to guide future actions that promote flexibility. It does not focus on developing resistance (i.e., planning for the worst-case scenario with prespecified minimum performance levels), since this is a more costly approach that may be vulnerable to unexpected occurrences.

Through its indicators and monitoring and explicit timeframe of updates from the NPCC every three years, the NYC approach takes into account that climate change may not proceed as the current climate change risk information describes and that adjustments will need to be made. Thus, the flexible adaptation pathways approach is robust not only to climate change, but to other sources of risk and uncertainty (e.g., socioeconomic) and uncertainties resulting from lack of data and information. It recognizes that uncertainty is unavoidable.

Not all flexible adaptation approaches use detailed downscaled climate scenarios as in NYC planning, since such downscaled scenarios may not characterize the likelihood of future changes completely and could potentially lead to maladaptation. However, New York City stakeholders have clearly requested climate risk information that includes state-of-the-art downscaled scenarios, especially as planning proceeds from early more-generalized risk assessment to detailed implementation. Haasnoot et al. (2012) describe the development of climate action plans that are scenarioneutral, with decisions that do not require information about the likelihood of different future scenarios. Specific pathway maps can help decision-makers to identify opportunities and potential lowregret measures (Haasnoot et al., 2013). Hall et al. (2012) have developed a similar approach for robust decision-making under uncertainty.

Aspects of the NYC flexible adaptation approach that could benefit from more development include the use of pathway maps that can help decision-makers identify opportunities, potential low-regret measures, and response sequences, and the potential for greater overall costs or productivity trade-offs. Pathway maps can give clear information on the effectiveness and timing of options, enabling analysts to assess under what conditions and what timescale a plan could fall (Haasnoot et al., 2012).

Wise et al. (in this volume) have identified several critical dimensions that could be more fully integrated into the research and practice of the adaptation pathway concept. These include the recognition that adaptation approaches could embody multidimensionality, interdependency, and intertemporality, while developing holistic indicators and monitoring, incorporating social processes, and leading to transformation. Table 1 documents how these elements can be applied to the New York City flexible adaptation approach, with specific examples and opportunities for next steps.

\subsection{Multidimensionality}

The first criterion examines whether the city acknowledges that climate adaptation is not separable from the cultural, political, economic, environmental, and developmental contexts in which it occurs and that adaptation is therefore only part of a range of 
Table 1

Application of adaptation pathways criteria to New York City.

\begin{tabular}{|c|c|c|c|}
\hline Criteria & Overview of application & Specific examples & Next steps \\
\hline Multidimensionality & $\begin{array}{l}\text { Climate mitigation and adaptation is } \\
\text { embedded in larger PlaNYC } \\
\text { sustainability initiative }\end{array}$ & $\begin{array}{l}2011 \text { PlaNYC addresses climate in } \\
\text { relation to public health, natural } \\
\text { systems, green building, waterfront, } \\
\text { and public engagement } \\
\text { NPCC includes experts from scientific, } \\
\text { political, and economics fields }\end{array}$ & $\begin{array}{l}\text { Expand NPCC to include more experts } \\
\text { from political, cultural, and other } \\
\text { societal sectors }\end{array}$ \\
\hline \multirow[t]{2}{*}{ Interdependency } & $\begin{array}{l}\text { Climate Change Adaptation Task Force } \\
\text { consists of all major sectors that provide } \\
\text { services in NYC; interdependencies are } \\
\text { recognized and addressed through task } \\
\text { force process }\end{array}$ & $\begin{array}{l}\text { Action to increase resilience in food } \\
\text { supply is driven by an underlying } \\
\text { strategy to improve the resiliency of } \\
\text { consumer access. A specific initiative in } \\
\text { the SIRR Report under this effort is to } \\
\text { ensure the availability of SNAP benefits } \\
\text { for vulnerable consumers during large- } \\
\text { scale power outages (SIRR, 2013) }\end{array}$ & $\begin{array}{l}\text { Recognize that actions in one area of the } \\
\text { city may affect people and property in } \\
\text { other areas of the city or region. For } \\
\text { example, construction of tidal barriers } \\
\text { can have implications beyond the } \\
\text { community that they are intended to } \\
\text { protect }\end{array}$ \\
\hline & $\begin{array}{l}\text { Efforts are also connected from Boston } \\
\text { to Washington, DC through NOAA's } \\
\text { RISA program in the urban Northeast } \\
\text { (CCRUN) }\end{array}$ & & \\
\hline \multirow[t]{2}{*}{ Intertemporality } & $\begin{array}{l}\text { Lock-in issues are addressed in NPCC } 1 \\
\text { with the call for adaptation to evolve } \\
\text { through time and actions to be } \\
\text { monitored and reassessed (Jacob et al., } \\
2010 \text { ) }\end{array}$ & $\begin{array}{l}\text { NPCC and the City will review observed } \\
\text { sea level rise every six years. If, by } 2025 \text {, } \\
\text { sea level rise surpasses the projected } \\
\text { metrics, the Building Code will be } \\
\text { amended }\end{array}$ & $\begin{array}{l}\text { Coordinate comprehensive resiliency } \\
\text { plan with hazard mitigation plan }\end{array}$ \\
\hline & & $\begin{array}{l}\text { Local Law } 42 \text { requires the Climate } \\
\text { Change Adaptation Task Force to update } \\
\text { risk assessment within one year of } \\
\text { updated climate projections, which are } \\
\text { required every three years }\end{array}$ & $\begin{array}{l}\text { Study ways to avoid path dependencies } \\
\text { and lock-ins }\end{array}$ \\
\hline $\begin{array}{l}\text { Holistic indicators } \\
\text { and monitoring }\end{array}$ & $\begin{array}{l}\text { NPCC has called for comprehensive } \\
\text { monitoring that includes not only } \\
\text { measuring changes in climate but also } \\
\text { in impacts, adaptations, and socio- } \\
\text { ecological factors (Jacob et al., 2010) }\end{array}$ & $\begin{array}{l}\text { A number of metrics for infrastructure } \\
\text { and built environment resilience are } \\
\text { identified by the SIRR (see Table } 2 \text { ) }\end{array}$ & $\begin{array}{l}\text { Include resiliency indicators in annual } \\
\text { progress updates }\end{array}$ \\
\hline \multirow[t]{2}{*}{$\begin{array}{l}\text { Societal processes } \\
\text { and transformation }\end{array}$} & $\begin{array}{l}\text { NYC has a long history of responding to } \\
\text { environmental challenges (Solecki and } \\
\text { Rosenzweig, 2004) }\end{array}$ & $\begin{array}{l}\text { New York's spirit of resilience } \\
\text { highlighted as response to Hurricane } \\
\text { Sandy }\end{array}$ & $\begin{array}{l}\text { Expand participatory processes beyond } \\
\text { the five hardest-hit communities so } \\
\text { that transformation is diffused through } \\
\text { entire city }\end{array}$ \\
\hline & $\begin{array}{l}\text { The response to Hurricane Sandy has } \\
\text { demonstrated the proactive and } \\
\text { resilient nature of city }\end{array}$ & $\begin{array}{l}\text { The process of the SIRR included } \\
\text { workshops and briefings by city } \\
\text { agencies with community members, } \\
\text { citywide organizations, and elected } \\
\text { officials }\end{array}$ & \\
\hline
\end{tabular}

Criteria are adapted from Wise et al. (in this volume).

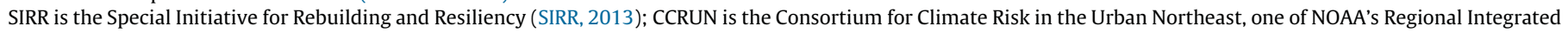

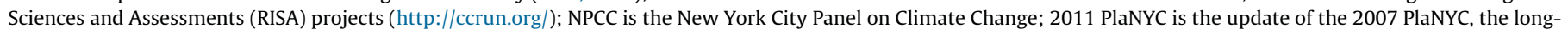
term plan for resilience and sustainability in New York City (NYC, 2011). SNAP is the Supplemental Nutrition Assistance Program.

societal responses. Regarding the application of the multidimensional concept to adaptation in New York City under Mayor Bloomberg's administration, all climate change responses are embedded in a larger, multidimensional framing of sustainability and resilience.

In September 2006, Mayor Michael Bloomberg created the Office of Long-Term Planning and Sustainability. The goal of the Office is to develop and implement a comprehensive plan, verifiable over time, to create a 'greener', more sustainable city given a projected population increase of 1 million additional people in the city by 2030 . The sustainability plan, known as PlaNYC, was released in April 2007, and recognized the importance of promoting both climate change mitigation and adaptation. For mitigation, PlaNYC defined a goal of a $30 \%$ reduction of greenhouse gas (GHG) emissions by 2030 from its 2005 level. For adaptation, it laid the groundwork for the New York City Climate Change Adaptation Task Force, established in 2008 (NYC, 2007). The latter was convened to identify and prioritize climate change risks for the critical infrastructure of the New York metropolitan region (note that this extends up to 100 miles from the 5 boroughs) and to develop and coordinate adaptation strategies to address these risks across the entire 'infrastructure-shed'. This effort was explicitly linked to the ClimAID Assessment of New York State (Rosenzweig et al., 2011b).

In its PlaNYC update in 2011, the City government put forth its initial citywide adaptation strategies, which encompassed multiple dimensions of adaptation planning, including public health, natural systems, green buildings, the waterfront, and public engagement (NYC, 2011), even though in practice much of the focus was on the resiliency of critical infrastructure. Engagement with these multiple dimensions was amplified in the SIRR.

\subsection{Interdependency}

This criterion involves recognition that responses need to be coordinated across spatial scales, sectors, and jurisdictional boundaries. In New York City, the Climate Change Adaptation Task Force consisted of all major sectors that provide infrastructure and health services, including water, transportation, energy, communications, and health. Interdependencies have been recognized and addressed explicitly through the task force process, which met quarterly as a group and monthly by workgroup 
through the period 2008-2010 (Zimmerman and Faris, 2010). The recognition of interdependency has been carried on explicitly in the SIRR process after Hurricane Sandy. Spatially, the task force process extends through the New York metropolitan region (Rosenzweig et al., 2011a), and connect with NOAA's Regional Integrated Science and Assessment program via the Consortium for Climate Risk in the Urban Northeast (CCRUN), which conducts stakeholder-driven adaptation research from Boston to Philadelphia.

A specific example of the recognition of interdependencies by the New York City adaptation process is the planned action to improve resilience in food supply in the SIRR. The stated goal is to enable continued operations of supporting systems upon which food supply depends, including power, liquid fuel, and transportation. A related example is the special initiative to ensure the availability of the Supplemental Nutrition Assistance Program (formerly known as Food Stamps) benefits for vulnerable consumers during large-scale power outages.

\subsection{Intertemporality}

The NPCC1 framing of flexible adaptation pathways explicitly recognized that locked-in, 'rigid' adaptation actions will eventually breach acceptable levels of societal risk and that adaptation needs to evolve through time. Monitoring and reassessment were the last in the cyclical adaptation steps described in the NPCC1 Adaptation Assessment Guidebook (Major and O'Grady, 2010). These have now been incorporated in the SIRR, which states that "The City and the NPCC will establish a set of interim metrics to be measured in 2025 that will indicate whether sea levels around New York appear to be rising at expected rates. Every six years - in conjunction with every second Construction Codes review cycle - the NPCC and the City will review observed sea level rise. If, by 2025 , sea level rise surpasses the metrics put forth by the City and the NPCC, the Building Code will be amended." The timetable for this effort may be advanced.

A further recognition of the intertemporality of the climate change adaptation challenge came through the passage of the New York City Council of Local Law 42 in September 2012 (just weeks before Hurricane Sandy) that requires the New York City Panel on Climate Change to update projections at least every three years and within a year of new IPCC projections, and the Climate Change Adaptation Task Force to do a risk assessment within one year of the new projections by the NPCC. The establishment of the NPCC and the Climate Change Adaptation Task Force coordinated as ongoing bodies is one means to monitor path dependency and to avoid lock-ins.

A new local law requires an updated comprehensive resiliency plan every four years in coordination with the City's regularly updated Hazard Mitigation Plan.

\subsection{Holistic indicators and monitoring}

The NPCC1 called for meaningful monitoring that includes not only measuring changes in climate, but also in impacts, adaptations, and socio-ecological factors (Fig. 4) (Jacob et al., 2010). After Hurricane Sandy, the SIRR report put forward a set of preliminary resiliency metrics for citywide infrastructure and the built environment that addresses coastal protection, buildings, insurance, utilities, liquid fuels, healthcare, telecommunications, transportation, parks, water and wastewater, solid waste, and food supply (Table 2). In regard to next steps, the NPCC2 is actively working to develop a climate change adaptation indicators and monitoring framework for New York City. The new law establishing the 'updateable' resiliency plan should also require the City's Office of Long-Term Planning and Sustainability to include the resiliency indicators in the annual progress update already issued by that office.

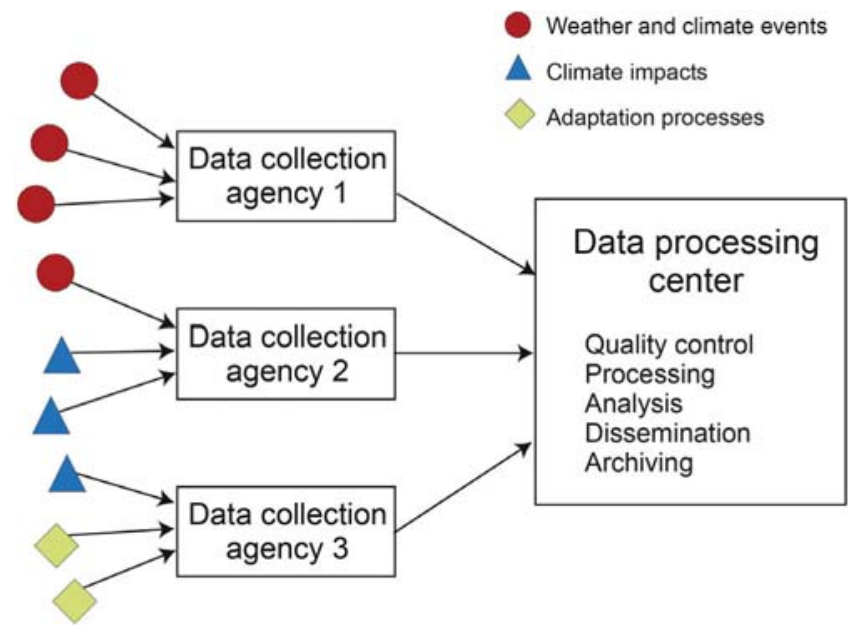

Fig. 4. Proposed structure and process of monitoring climate change, impact, and adaptation parameters, and for translating them into indicators for New York City (Jacob et al., 2010).

\subsection{Societal processes and transformation}

New York City has a long history of responding to environmental challenges (Solecki, 2012; Solecki and Rosenzweig, 2004), and the response to Hurricane Sandy has demonstrated yet again the proactive culture of the city, this time in regard to climate change. Fig. 5, taken from the inside cover of the SIRR report, is representative of New York's embrace of resilience within the context of its own self-identity. The scope and scale of the planning, encompassing $\$ 19.5$ billion worth of proposed actions for New York City is indeed transformative. Another program contributing to adaptive transformation, Rebuild by Design, is a region-wide competition for special resiliency projects, sponsored by the Executive Branch of the US Federal Government.

The creation of the SIRR also recognized that societal processes are essential for effective and transformative adaptation. From November 2012 to June 2013, the City conducted eleven public workshops and briefed more than 320 business, civic, communitybased, environmental, faith-based, and labor organizations. Nearly 100 government partners and elected offices were engaged and briefed (SIRR, 2013). The process focused especially on the neighborhoods hardest hit by Sandy, including the Brooklyn-Queens waterfront, southern Queens, the east and south shores of Staten Island, southern Brooklyn, and southern Manhattan. These were presented not as 'one-off events but rather a coordinated series of workshops and briefings, aimed at engaging citizens with the transformative plans of the SIRR over time.

\section{Barriers to implementation}

There are several key behavioral and political-economy barriers faced by New York City in implementing adaptation plans. These include a cultural bias toward 'toughness,' as evidenced by the opening quote of the SIRR (Fig. 5). This concept of toughness may have contributed to a dampening of debate of the retreat option within NYC. In contrast, New York State has implemented the NY Smart Home Buyout Program, a plan with the goal of transforming highly-damaged neighborhoods into permanent green space. Oakwood Beach, Staten Island, where Sandy brought a 20-foot storm surge that crashed over roofs and killed three people, is one community in New York City to adopt this option. Four hundredeighteen private properties are involved in the buy-out.

On the political side, the City is now facing a barrier related to the transient nature of political administrations. Since January, 
Table 2

Selected citywide infrastructure and built-environment resiliency metrics (preliminary).

\begin{tabular}{|c|c|}
\hline Category & Metrics \\
\hline Coastal protection & $\begin{array}{l}\text { Federal dollars secured for coastal protection projects } \\
\# \text { of buildings with reduced coastal risk due to coastal protection projects }\end{array}$ \\
\hline Buildings & $\begin{array}{l}\text { \# of buildings implementing Core Flood Resiliency Measures } \\
\text { \# of square feet of residential and non-residential buildings implementing Core Flood Resiliency Measures }\end{array}$ \\
\hline Insurance & $\begin{array}{l}\% \text { of residences in } 100 \text {-year floodplain purchasing flood insurance } \\
\text { Average premium paid for The National Flood Insurance Program (NFIP) policies }\end{array}$ \\
\hline Utilities & $\begin{array}{l}\% \text { of electric generation capacity in the } 500 \text {-year floodplain able to remain online after a } 500 \text {-year flood } \\
\text { Maximum \% of peak load that could be lost due to failure of any one substation } \\
\% \text { of assets at or above their loading limits during peak demand periods (e.g., during heat waves) } \\
\# \text { of miles of cast iron and bare steel gas mains in the } 500 \text {-year floodplain } \\
\% \text { of steam generation capacity in the } 500 \text {-year floodplain able to remain online after a } 500 \text {-year flood }\end{array}$ \\
\hline Liquid fuels & $\begin{array}{l}\% \text { of gas stations with quick-connects for generators } \\
\% \text { of regional fuel terminal capacity in the } 100 \text {-year floodplain hardened against a } 100 \text {-year flood } \\
\% \text { of regional refining capacity in the } 100 \text {-year floodplain hardened against a } 100 \text {-year flood }\end{array}$ \\
\hline Healthcare & $\begin{array}{l}\% \text { of hospital beds in } 500 \text {-year floodplain meeting resiliency requirements } \\
\% \text { of nursing homes and adult care beds in } 100 \text {-year floodplain meeting resiliency requirements }\end{array}$ \\
\hline Telecommunications & \# of critical telecommunications facilities implementing Core Flood Resiliency Measures \\
\hline Transportation & $\begin{array}{l}\text { \# of lane-miles reconstructed or resurfaced } \\
\% \text { of New York City transportation assets adapted for climate change resiliency }\end{array}$ \\
\hline Parks & $\begin{array}{l}\text { \% of facilities in Sandy inundation zone upgraded for greater resiliency } \\
\text { \# of trees inspected and pruned } \\
\text { \# of cubic yards of beach sand nourishment }\end{array}$ \\
\hline Water and wastewater & $\begin{array}{l}\text { \# of wastewater facilities or assets protected or raised above the } 100 \text {-year floodplain } \\
\% \text { of combined sewer area runoff managed by green infrastructure } \\
\text { \# of new sewer miles built in areas with no or partial sewers } \\
\text { \# of areas served by Bluebelt (wetlands) projects built citywide } \\
\% \text { of water quality samples complying with Surface Water Treatment Rule standard for turbidity }\end{array}$ \\
\hline Solid waste & \# of New York City Department of Sanitation (DSNY) facilities protected or raised above the 100 -year floodplain \\
\hline Food supply & $\begin{array}{l}\text { \# of grocery stores with generators or quick connects for generators } \\
\% \text { of New York City Department of Citywide Administrative Services (DCAS) food procurement backstopped with more resilient distributors }\end{array}$ \\
\hline
\end{tabular}
Source:SIRR (2013).

2014 a new mayoral administration is in place in New York City, and at the time of writing this article, has just begun to signal its direction in regard to climate change, adaptation, and transformation. In regard to the economy, the promise of multiple billions for rebuilding and resiliency from the US Federal Government has been reduced in order to share funding for rebuilding after climate disasters in other parts of the nation, and accessing the funds that are still available has proved difficult because of alleged federal administration "red-tape" requirements.

A further barrier has been the balkanization of the rebuilding and resiliency efforts due to separate targeted funding of New York
State, New York City, and New Jersey by the federal government. This has hindered the development of a regional approach needed for true transformation.

On the other hand, New York City has a rich history of leadership on environmental issues, and this environmental stewardship is coming to the fore again in regard to climate change. The City's foresight in protecting its upstate water supplies since the 1840s, its development of major parks throughout the five boroughs in the early 1900s, and its leadership on clean air in the 1970s all now resonate as it takes up the challenge of responding to climate change (Solecki, 2012).

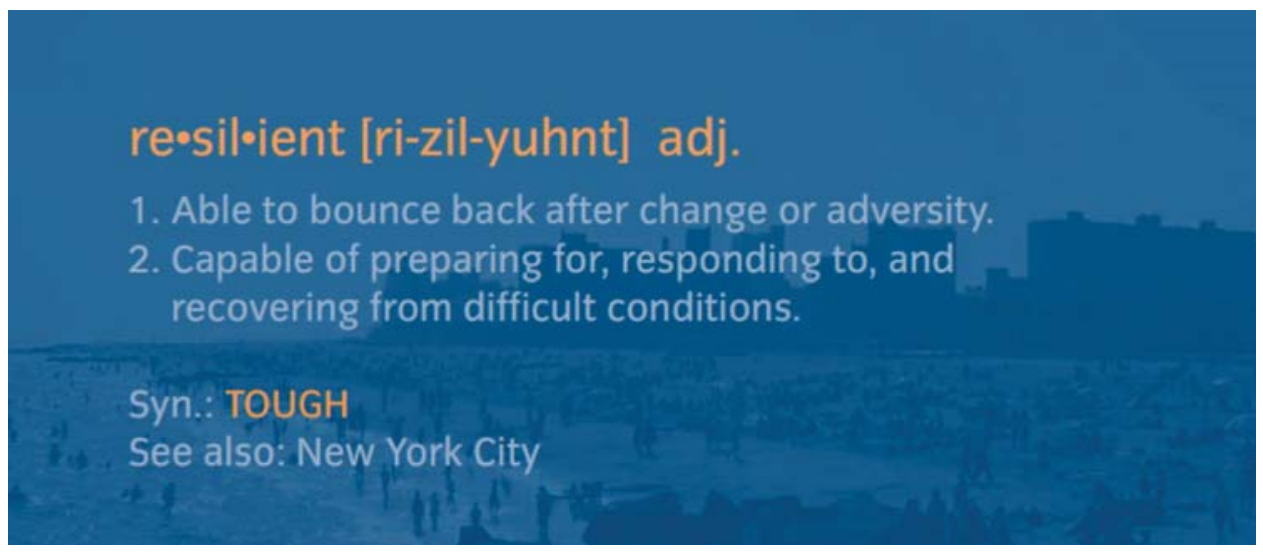

Fig. 5. Inside cover of New York City's Special Initiative on Rebuilding and Resiliency Report (SIRR, 2013). 


\section{Usability of climate information provided by the NPCC}

A key part of the interaction between scientists and decisionmakers in the adaptation pathway process in New York City is the creation of an ongoing assessment of current climate trends and a set of hyper-local projections by the NPCC. The process was iterative, with specific stakeholder input on which variables to include and on what risk levels to present. One lesson learned from both the NPCC1 and NPCC2 stakeholder interactions was that initiation of the interactions should take place as early as possible in the projection development process. The process was especially challenging after Hurricane Sandy for the NPCC scientists, since the projections were needed as direct inputs to the SIRR.

City agencies, representatives, and other stakeholders in New York City are very interested in whether there are observable local trends in the current climate. NPCC analyses show that temperature has been increasing, precipitation variability has become more extreme, and sea level is rising in the New York metropolitan region (NPCC, 2013). Mean annual temperature in New York City has increased $2.2^{\circ} \mathrm{C}\left(4.4^{\circ} \mathrm{F}\right)$ from 1900 to 2011. Mean annual precipitation has increased $19.6 \mathrm{~cm}$ (7.7 inches) from 1900 to 2011 (a change of $1.4 \%$ per decade). Year-to-year precipitation variability was significantly greater from 1956 to 2011 than from 1900 to 1955 . Sea level in New York City (at the Battery) has risen $33.5 \mathrm{~cm}(1.1 \mathrm{ft})$ since 1900 . Stakeholders also asked for up-to-date future climate change projections for use in their planning processes.

\subsection{Climate scenarios}

The current NPCC2 projections provide model-based outcomes for climate variables from 35 GCMs (24 for sea level rise) and two Representative Concentration Pathways (RCP4.5 and RCP8.5) downscaled to the New York metropolitan region (NPCC, 2013). Observed data are from the National Oceanic and Atmospheric Administration (NOAA), National Climatic Data Center (NCDC), United States Historical Climatology Network (USHCN), Version 2 (Menne et al., 2009). The projections are presented as 10th, 25th, 75th, and 90th percentiles. For sea-level rise, a new six-component approach was developed to take into account both global and regional factors (NPCC, 2013). Changes in both means and extreme events are projected. (see Supplementary data Table 1 and Table 2 )

These projections are accompanied by explicit information about their uncertainties especially at finer scales. Sources of uncertainty include the random nature of some parts of the climate system, poor representation of some processes in climate models, and limitations in observed data (especially true in heterogeneous urban areas). The projections are not true probabilities, and the potential for error is explicitly acknowledged.

The NPCC approach to climate scenarios is similar to that used in the Thames Estuary 2100 Project in that outputs from climate models are used, but with recognition of their limitations and the need to incorporate the concept of risk (Ranger et al., 2013). Rather than only relying on them for projections, the models also are used to develop physical understanding of climate processes in order to better bound potential future change. Furthermore, the NPCC projections do not rely on climate models alone. For example, uncertainties in sea level projections are explored through a sixcomponent process, only two of which are based on climate models.

Both the NPCC1 and the NPCC2 projections (developed after Hurricane Sandy) illustrate a broad-based acceleration of climate change in coming decades in New York City. When compared to the NPCC1 2009 projections, the NPCC2 results contained no dramatic shifts or changes with respect to any one specific climate risk metric or variable. The short time span between projections (i.e.,
4 years compared to the IPCC assessment report cycle of 7 years) will allow the city to better evolve its adaptation plans with the latest science. Even though the changes were not dramatic this time, climate-system tipping points or leaps of advancement in science are not out of the question in the future.

\subsection{Extreme events}

A special need exists for clarity in information regarding extreme events, since it is very difficult to determine trends on local scales, and thus uncertainties in even qualitative projections are large. In regard to hurricanes, there have been observed increases in strength and in the number of the strongest (Category 4 and 5) hurricanes in the North Atlantic since the early 1980s (NPCC, 2013). The NPCC2 projected that the number of intense hurricanes, extreme hurricane winds, and intense hurricane precipitation were more likely than not ( $>66 \%$ probability of occurrence) to increase in the North Atlantic Basin (NPCC, 2013). In regard to downpours, the NPCC documented a 75\% increase in heaviest rain events in the US Northeast over the last 50 years (Horton et al., 2014).

\subsection{NPCC and SIRR}

Understanding climate change in New York City has been refined with respect to projections and uncertainty. Importantly, this is an early illustration of the need for and the use of updated climate change projections linked to policy-making on an on-going basis. The NPCC2 Climate Risk Information 2013 Report presents climate projections and uncertainties to facilitate risk-based decision-making (NPCC, 2013). It uses ranges of model-based outcomes and likelihoods based on scientific literature, and presents outcomes that encompass multiple climate models and a range of future greenhouse gas emissions. The NPCC is careful to note that these model-based outcomes do not encompass the full range of possible futures. The close and frequent interaction of researchers and city officials resulted in the NPCC's products being not only useful but usable, an important distinction as described by Lemos et al. (2012).

\section{Transferability and cities as first responders}

Turning to the question of how useful NYC's approaches may be to other cities - whether mega, large, medium, or small and across a range of incomes - we find that three aspects are especially transferable. The first is the overall concept of flexible adaptation pathways, since it is size and development-stage neutral. The leaders and citizens of any city can come together to embrace the need for flexible responses to extreme climate events and climate change through time.

The second transferable element is the metropolitan region approach that was taken in the first phase of the NYC effort. NYC provided an invaluable service by bringing together the managers of the critical infrastructure in the entire infrastructure-shed extending more than $100 \mathrm{~km}$ beyond the municipal borders of the City (Rosenzweig et al., 2011a) and this approach could usefully be adopted everywhere (Rosenzweig et al., 2014). Cities all over the world have centers and peripheries: the domain of climate change responses needs to encompass them both.

The final transferable element is the process by which climate risk information is co-generated by stakeholders and scientists. While every city may not have the climate science expertise available within its administrative boundaries, groups such as the Urban Climate Change Research Network (UCCRN) are working with cities around the world to develop their own science-based information for key decisions that can be tracked through time (Rosenzweig et al., 
2011c). On the horizon is the development of a climate change urban indicators and monitoring system that can be shared across cities as well.

\subsection{First responders}

Led by New York and other early-adopter cities, cities are emerging as first responders to climate change. These cities are important test-beds for the adaptation pathways concept. In evidence of this, cities are committing to a series of actions to promote equitable and effective adaptation as well as mitigation. With ICLEI taking a leading role, city groups have cooperated to insert cities into the international United Nations Framework Convention on Climate Change (UNFCCC, 2013). A key outcome of this effort to include cities in the UNFCCC is the Durban Adaptation Charter for Local Governments (DAC, 2013) (Table 3). By signing the charter, cities commit to a series of actions to promote equitable and effective adaptation. As of June 2014, there are over 1100 signatories to the Charter.

Action on climate issues at national and international levels has been limited and controversial as different stakeholders debate the need for climate policies. In contrast, cities are responding to climate change with markedly little contention. Beyond the local level, cities are playing a role in catalyzing national and international responses. Groups such as the C40 Large Cities Climate Group (C40), the World Mayors Council on the Climate Change (WMCCC), and ICLEI-Local Governments for Sustainability (ICLEI, 2013) have all helped cities come together to pledge reductions in greenhouse gas emissions and plan adaptations.

As of December 2012, over 280 mayors and other local authorities have signed the voluntary Global Cities Covenant on Climate (also known as the Mexico City Pact). The phenomenon of cities as first responders is not limited to early-adopter megacities such as New York and Mexico City, since city climate change networks such as ICLEI are mobilizing actions by a growing number of small, medium, and large cities to reduce greenhouse gas emissions and plan adaptations. The C40 Large Cities Climate Group has teamed up with the Clinton Climate Initiative and the World Bank to promote mitigation and adaptation activities by cities (C40, 2013; Clinton Climate Initiative, 2013). A few examples of current program initiatives of C40 include: low-carbon transportation, waste management, and outdoor lighting.

Table 3

The Durban Adaptation Charter.

Clause 1. Mainstream adaptation as a key informant of all local government development planning

Clause 2. Understand climate risks through conducting impact and vulnerability assessments

Clause 3. Prepare and implement integrated, inclusive and long-term local adaptation strategies designed to reduce vulnerability

Clause 4 . Ensure that adaptation strategies are aligned with mitigation strategies

Clause 5. Promote the use of adaptation that recognizes the needs of vulnerable communities and ensures sustainable local economic development

Clause 6. Prioritize the role of functioning ecosystems as core municipal green infrastructure

Clause 7. Seek the creation of direct access to funding opportunities

Clause 8. Develop an acceptable, robust, transparent, measurable, reportable and verifiable (MRV) register

Clause 9. Promote multi-level and integrated governance and advocate for

partnerships with sub-national and national governments on local climate action

Clause 10. Promote partnerships at all levels and city-to-city cooperation and knowledge exchange

Source: http://www.durbanadaptationcharter.org/Resources/Durban_Adaptation_ Charter_5_December_2011.pdf.
The growth of the DAC, C40, and the World Mayors Council and other activities illustrates that individual cities are developing and operationalizing decision frameworks for accomplishing these goals under conditions of increasing climate risks. Is the adaptation pathways approach being successfully transferred to other cities beyond New York, and other early-adopter cities? Adaptation plans in several cities show most of the elements of flexible adaptation pathways, including London, Tokyo, Quito, and Mexico City, while many other cities have some of the elements (Rosenzweig et al., 2011c). Such cities include Sorsogon City, Philippines; Kokkola, Finland; Maputo, Mozambique; Toronto, Canada; and Seattle, USA (Rosenzweig et al., 2011c).

\section{Why cities are emerging as first responders and pros and cons}

Cities are emerging as first responders for climate change for a variety of reasons, including their decades-long experience in addressing multiple environmental stresses. Further, they are often on the front lines in responding to climate disasters, especially with a focus on aiding vulnerable communities. Many of these factors can be seen as providing a foundation for the development and implementation of flexible adaptation pathways for climate change.

\subsection{Ameliorating multiple environmental stresses}

Cities have long-standing experience in tackling environmental challenges on their own and with taking the lead in environmental management. Environmental challenges related to water supply, waste disposal, and air quality are not new developments; cities have had to deal with these challenges for years. Cities have also long been establishing parks and green spaces to repair damaged urban ecosystems and improve sustainability. By considering climate change as another environmental stressor that must be managed, cities can build on their decades of experience in goal setting and implementation of remediation measures to improve environmental and human outcomes.

\subsection{Responding to disasters}

Cities also have experience in dealing with a variety of disasters, including those related to climate, and urban leaders have developed "best practices" they can utilize in responding to disasters. To assist with this task, the United Nations Office for Disaster Risk Reduction (UNISDR) is responsible for promoting risk reduction efforts around the world. UNISDR's "Making Resilient Cities" campaign aims to reduce urban disaster risk by raising awareness of common issues and providing guidance and tools to affected cities (UNISDR, 2013). Knowing that disasters are the product of interactions between natural processes and human vulnerabilities, many urban leaders understand that preparedness is essential and are ready to 'make the connection' between the need to mitigate greenhouse gas emissions and develop climate resilience.

\subsection{Helping vulnerable populations}

Cities have also long recognized the need for services for disadvantaged citizens, and thus are more likely to respond to exacerbated risks to their more vulnerable populations. The fastest growing group in global cities is the urban poor. These households, along with pre-existing vulnerable populations like women, minority groups, the elderly, and the very young are most at risk from climate change impacts. They have the lowest ability to cope with natural disasters and are heavily dependent on public services 
for their needs. One example of how climate impacts disproportionately damage vulnerable populations is the effect of extreme rainfall on those living in the favelas of Rio de Janeiro, Brazil. Extreme precipitation events impact the poor living in these neighborhoods by destroying homes and livelihoods, and often families have no means of coping with these losses (Sherbinin and Hogan, 2011).

\subsection{Science in place/science in time}

While the elements of multidimensionality, intertemporality, indicators and monitoring, social processes and transformation are all essential, we propose another critical element brought forward by the adaptation pathway experience of Hurricane Sandy in particular and of New York more broadly. As cities work to meet the challenges of climate change, it is vital that they understand the science of urban climate and its impacts and integrate scientific knowledge with adaptation investments. In turn, scientists must understand the unique needs of urban populations and decision-makers in order to continue to develop the field of urban climate change research. In short, credible science-based climate risk information needs to be 'in place' and 'in time.' Moreover, scientists, decision-makers, and other stakeholders must work together closely and intentionally to ensure that information is usable (Lemos et al., 2012). The growing interest in these endeavors is represented by an increase in scholarly articles on climate change and cities (see Supplementary data Fig. 1).

There is an urgent need for a stronger science base for urban decision-making as cities become a major force in climate change response. The Urban Climate Change Research Network (UCCRN) Assessment Report on Climate Change and Cities (ARC3) is structured to address this need. Developed as roughly analogous to the Intergovernmental Panel on Climate Change (IPCC) but aimed at cities rather than nations, UCCRN is creating a process through which urban researchers provide vital updated climate risk information that can contribute to specific and targeted city decision-making on both mitigation and adaptation. The network links scholars and decision-makers in a spectrum of cities in all parts of the globe. UCCRN's First Assessment Report on Climate Change and Cities (ARC3) was published in 2011 (Rosenzweig et al., 2011c), and the Second Assessment Report (ARC3-2) is now underway. The goal of the ARC3 assessments is to provide a critical knowledge base and benchmarking function that enables cities to learn over time as both climate change and climate change responses unfold and thus situate relevant climate risk information and updated science 'in place and in time' for all cities.

\subsection{Pros and cons of cities as first responders}

There are several 'pros' or benefits related to the concept of 'cities as first responders.' The first is that cities are cultural leaders and media centers and that they are thus well-placed to lead outreach on climate change. For example, The Years of Living Dangerously, a major series on climate change has been produced in New York City and broadcast nationwide in the US by a major cable company following Hurricane Sandy.

Second, cities are well placed to communicate with state and federal levels of government about the need for climate preparedness not just for themselves but for suburban and rural areas as well. They are thus leading 'from the bottom up.' Furthermore, they are also now engaging in the international climate change negotiation process, bringing the message that local governments (both urban and rural) can provide practical services in achieving both mitigation and adaptation. On the other hand, city momentum and learning may not trickle down to rural areas, and furthermore, cities may 'hog' federal investments for resilience, leaving rural areas to suffer.

\section{Conclusions: lessons from Hurricane Sandy}

The narrative approach used in the paper to evaluate the flexible adaptation pathway undertaken by New York City has been useful to deepen understanding of and appreciation for climate risk management. The criteria used in Wise et al. (in this volume) could be improved by the explicit inclusion of a topic on co-generation of climate science by scientists and stakeholders. We have found this to be an essential element in the development of the flexible adaptation approach in NYC.

The experience of Hurricane Sandy has had a major effect on coastal storm protection planning not only in New York City, but also in New York State, nationally and even internationally, with the explicit recognition of increasing risks due to climate change in coastal areas now thoroughly accepted in public discourse. The Special Initiative for Rebuilding and Resiliency (SIRR) is the embodiment of that embrace of climate risks at the New York City scale; Rebuild by Design is a major effort at the national level, and the naming of Mayor Bloomberg as Secretary General Ban KiMoon's Special Envoy on Climate Change and Cities is highlighting these issues internationally.

Rather than change the flexible adaptation pathway approach initially developed in New York City, the experience of Hurricane Sandy has grounded, reinforced, and expanded it. Sandy and its aftermath have actualized it from a generalized heuristic to a specific trajectory with milestones. Specifically, Hurricane Sandy has become a tipping point as the acceptable level of climate risk plummeted, and increasing risks due to climate change were explicitly included in rebuilding. Investment and action were mobilized, creating a transformative new development trajectory.

Prior to Hurricane Sandy, incremental adaptation strategies were envisioned so as to avoid disruptions of current systems. After Sandy, it has become clear that with over 20 million people living in the New York metropolitan region, the presence of large critical and interdependent infrastructure systems, and the significant risks of exacerbated coastal flooding posed by the NPCC sea level rise projections, transformation at the full regional scale is required.

One key lesson is that the flexible adaptation strategies need to be locally appropriate yet regionally coordinated. The mechanisms of the US Congressional Appropriations have been a balkanizing force, with New York City, New York State, and New Jersey all developing separate approaches to rebuilding and resiliency. This makes for a patchwork, rather than regional fabric of resiliency. The Rebuild by Design report-writers acknowledge the need for regional coordination: 'Ideas [of the design teams] were developed to address local needs in the region affected by Sandy, but the designers and scholars who produced them are all-too-aware that the security threats stemming from climate change know no borders (Rebuild by Design, 2014).'

The challenge, however, is to sustain the transformative trajectory. Groups such as the New York City Panel on Climate Change, the Consortium for Climate Risk in the Urban Northeast, the New York Resiliency Institute, and the Science and Resilience Institute @ Jamaica Bay are helping to provide the knowledge base related to innovative adaptation options and underlying social factors related to widespread adoption. These will enable the incorporation of transformative adaptation into flexible adaptation pathways and risk management paradigms throughout the entire region. Internationally, sustaining the momentum toward adaptive transformation in cities needs to be nurtured at all levels of governance, up to and including the United Nations Framework Convention on Climate Change. 


\section{Disclaimer}

The authors wrote this paper as independent research scientists. The views expressed are their own and do not reflect their roles as Co-Chairs of the New York City Panel on Climate Change.

\section{Acknowledgment}

We thank Elisabeth Gawthrop, Stephen Solecki, Somayya Ali, Erik Mencos Contreras and Daniel Bader for their excellent research assistance on this paper. CR acknowledges Dr. Jack Kaye, Associate Director for Research, Earth Science Division, Science Mission Directorate at NASA, and NASA WBS\# 144598.04.01.01.17.

\section{Appendix A. Supplementary data}

Supplementary data associated with this article can be found, in the online version, at doi:10.1016/j.gloenvcha.2014.05.003.

\section{References}

Aerts, J.C.J.H., Lin, N., Botzen, W.J.W., Emanuel, K., de Moel, H., 2013. Low-probability flood risk modeling for New York City. Risk Anal. 33, 772-788.

Baker, E.J., Broad, K., Czajkowski, J., Meyer, R., Orlov, B., 2012. Risk Perceptions and Preparedness among Mid-Atlantic Coastal Residents in Advance of Hurricane Sandy. Working Paper \#2012-18 from the Risk Management and Decision Processes Center. The Wharton School, University of Pennsylvania, Philadelphia, PA.

Blake, E.S., Kimberlain, T.B., Berg, R.J., Cangialosi, J.P., Beven II, J.L., 2013. Tropical Cyclone Report: Hurricane Sandy (AL182012). National Hurricane Center.

Boyd, E., 2011. Fatalities Due to Hurricane Katrina's Impacts in Louisiana. (Ph.D. Thesis)Louisiana State University.

C40 Cities Climate Leadership Group, 2013. Available at: http://www.c40cities.org/ partners (accessed 31.07.13).

Clinton Climate Initiative, 2013. Available at: http://www.clintonfoundation.org/ main/our-work/by-initiative/clinton-climate-initiative/programs/c40-cci-cities. html (accessed 31.07.13).

Dixon, L., Clancy, N., Bender, B., Kofner, A., Manheim, D., Zakaras, L., 2013. Flood Insurance in New York City Following Hurricane Sandy. Center for Risk and Catastrophic Risk Management and Compensation. Report Prepared for the New York City Mayor's Office of Long-Term Planning and Sustainability. Available at: http://www.rand.org/content/dam/rand/pubs/research_reports RR300/RR328/RAND_RR328.pdf (accessed 23.03.14).

Durban Adaptation Charter for Local Governments, 2013. Available at: http:// www.durbanadaptationcharter.org/Resources/Durban_Adaptation_Charter_5_December_2011.pdf (accessed 31.07.13).

Federal Emergency Management Agency (FEMA), 2013. Effective and Advisory FEMA 100-Year Flood Zones. Available at: http://www.nyc.gov/html/dcp html/flood_resiliency/index.shtml (accessed 21.03.14).

Folke, C., Carpenter, S.R., Walker, B., Scheffer, M., Chapin, T., Rockström, J., 2010 Resilience thinking: integrating resilience, adaptability and transformability Ecol. Soc. 15, 20. Available at: http://www.ecologyandsociety.org/vol15/iss4/ art20/ (accessed 21.03.14).

Haasnoot, M., Middelkoop, H., Offermans, A., van Beek, E., van Deursen, W.P.A. 2012. Exploring pathways for sustainable water management in river deltas in a changing environment. Clim. Change 115, 795-819, http://dx.doi.org/10.1007/ s10584-012-0444-2.

Haasnoot, M., Kwakkel, J.H., Walker, W.E., ter Maat, J., 2013a. Dynamic adaptive policy pathways: a method for crafting robust decisions for a deeply uncertain world. Glob. Environ. Change 23, 485-498, http://dx.doi.org/10.1016/j.gloenvcha.2012.12.006.

Haasnoot, M., Kwakkel, J.H., Walker, W.E., ter Maat, J., 2013b. Dynamic adaptive policy pathways: a method for crafting robust decisions for a deeply uncertain world Glob. Environ. Change 23, 485-498.

Hall, T.M., Sobel, A.H., 2013. On the impact angle of Hurricane Sandy's New Jersey landfall. Geophys. Res. Lett. 40, 2312-2315, http://dx.doi.org/10.1002 grl.50395.

Hall, J.W., Lempert, R.J., Keller, A., Hackbarth, A., Mijere, C., McInerney, D., 2012. Robust climate policies under uncertainty: a comparison of robust decision making and info-gap methods. Risk Anal. 32, 1657-1672.

Hallegatte, S., 2009. Strategies to adapt to an uncertain climate change. Glob. Environ. Change 19, 240-247.

Hewson, T., 2012. ECMWF forecasts of 'Superstorm Sandy'. ECMWF Newslett. 133

Horton, R., Rosenzweig, C., Gornitz, V., Bader, D., O’Grady, M., 2010. Climate Risk Information. Ann. N. Y. Acad. Sci. 1196, 147-228.

Horton, R., Yohe, G., Easterling, W., Kates, R., Ruth, M., Sussman, E., Whelchel, A. Wolfe, D., Lipschultz, F., 2014. In: Melillo, J.M., Terese (T.C.) Richmond, Yohe, G.W. (Eds.), Ch. 16: Northeast. Climate Change Impacts in the United States:
The Third National Climate Assessment. U.S. Global Change Research Program, 16-1-nn.

ICLEI - Local Governments for Sustainability, 2013. Available at: http://www icleiusa.org/about-iclei/faqs/faq-about-iclei-local-governments-for-sustainability (accessed 31.07.13).

IPCC, 2013. Working Group I Fifth Assessment Report. IPCC. Cambridge University Press.

Jacob, K., Blake, R., Horton, R., Bader, D., O'Grady, M., 2010. Chapter 7: indicators and monitoring. Ann. N. Y. Acad. Sci. 1196, 127-142, http://dx.doi.org/10.1111/ j.1749-6632.2009.05321.x

Kates, R.W., Travis, W.R., Wilbanks, T.J., 2012. Transformational adaptation when incremental adaptations to climate change are insufficient. Proc. Natl. Acad. Sci. 109, 7156-7161.

Kunreuther, H., 2008. Reducing losses from catastrophic risks through long-term insurance and mitigation. Soc. Res. 75, 905-930.

Lemos, M.C., Kirchhoff, C., Ramprasad, V., 2012. Narrowing the climate information usability gap. Nat. Clim. Change 2, 789-794, http://dx.doi.org/10.1038/nclimate1614

Lowe, J., Reeder, T., Horsburgh, K., Bell, V., 2008. Using the New TE2100 Science Scenarios. UK Environment Agency. Presentation.

Major, D.C., O'Grady, M., 2010. Adaptation Assessment Guidebook. Ann. N. Y. Acad. Sci. 1196, 229-292.

McCulloch, A., 2013. Hurricane Sandy: A Look Back. Significance. Royal Statistical Society.

Menne, M.J., Williams, C.N., Vose, R.S., 2009. The United States Historical Climatology Network monthly temperature data - version 2. Bull. Am. Meteorol. Soc. 90 993-1107.

Michel-Kerjan, E., Kunreuther, H., 2011. Redesigning flood insurance. Science 333, 408-409.

New York City Panel on Climate Change (NPCC), 2010. Climate change adaptation in New York City: building a risk management response. In: Rosenzweig, C., Solecki, W. (Eds.), Prepared for Use by the New York City Climate Change Adaptation Task Force. Annals of the New York Academy of Sciences, New York, NY, 354 pp.

New York City Panel on Climate Change, 2013. Climate risk information 2013: observations, climate change projections, and maps. In: Rosenzweig, C., Solecki, W. (Eds.), Prepared for use by the City of New York Special Initiative on Rebuilding and Resiliency. NPCC2, New York, NY.

NYC, 2007. PlaNYC: A Greener, Greater New York. The City of New York. Available at: http://nytelecom.vo.llnwd.net/o15/agencies/planyc2030/pdf/full_report_2007.pdf (accessed 21.03.14)

NYC, 2011. PlaNYC April 2011 Update: A Greener, Greater New York. The City of New York. Available at: http://nytelecom.vo.llnwd.net/o15/agencies/planyc2030/pdf/planyc_2011_planyc_full_report.pdf (accessed 21.03.14).

Ranger, N., Millner, A., Dietz, S., Fankhauser, S., Lopez, A., Ruta, G., 2010. Adaptation in the UK: A Decision-making Process. Grantham Research Institute on Climate Change and the Environment and Center for Climate Change Economics and Policy

Ranger, N., Reeder, T., Lowe, J., 2013. Addressing ‘deep’ uncertainty over long-term climate in major infrastructure projects: four innovations of the Thames Estuary 2100 Project. EURO J. Decis. Processes 1 (3-4), 233-262.

Rebuild by Design, 2014. Rebuild by Design: A Regional Analysis, In: http:// www.rebuildbydesign.org/research/.

Reeder, T., Ranger, N., 2011. How do you adapt in an uncertain world? Lessons from the Thames Estuary 2100 project. Expert Perspectives Series Written for the World Resources Report 2010-2011. Washington, DC. . Available at: http:/ www.worldresourcesreport.org/files/wrr/papers/wrr_reeder_and_ranger_uncertainty.pdf (accessed 21.03.14).

Rosenzweig, C., Solecki, W.D. (Eds.), 2001. Climate Change and a Global City: The Potential Consequences of Climate Variability and Change - Metro East Coast. Report for the U.S. Global Change Research Program, National Assessment of the Potential Consequences of Climate Variability and Change for the United States. Columbia Earth Institute, New York, 224 pp.

Rosenzweig, C., Solecki, W.D., Blake, R., Bowman, M., Faris, C., Gornitz, V., Horton, R., Jacob, K., LeBlanc, A., Leichenko, R., Linkin, M., Major, D., O'Grady, M., Patrick, L. Sussman, E., Yohe, G., Zimmerman, R., 2011a. Developing coastal adaptation to climate change in the New York City infrastructure-shed: process, approach tools, and strategies. Clim. Change 106, 93-127, http://dx.doi.org/10.1007| s10584-010-0002-8.

Rosenzweig, C., Solecki, W., DeGaetano, A., O'Grady, M., Hassol, S., Grabhorn, P., 2011b. Responding to climate change in New York State: the ClimAID integrated assessment for effective climate change adaptation. Ann. N. Y. Acad. Sci. 1244, 2-649.

Rosenzweig, C., Solecki, W.D., Hammer, S.A., Mehrotra, S., 2011c. Climate Change and Cities: First Assessment Report of the Urban Climate Change Research Network. Cambridge University Press, Cambridge, UK.

Rosenzweig, C., Bader, D., Ibrahim, S.A., 2014. Enhancing Climate Resilience in Metropolitan Regions. Report prepared for the German Federal Enterprise for International Cooperation (GIZ)

Sherbinin, A., Hogan, D., 2011. Climate-proofing Rio de Janeiro. Brazil in Blake et al., 2011. Urban climate: processes, trends, and projections. In: Rosenzweig, C., Solecki, W.D., Hammer, S.A., Mehrotra, S. (Eds.), Climate Change and Cities: First Assessment Report of the Urban Climate Change Research Network. Cambridge University Press, Cambridge, UK, pp. 43-81.

Special Initiative for Rebuilding and Resiliency (SIRR), 2013. A Strong, More Resilient New York. The City of New York. Available at: http://www.nyc.gov/html sirr/html/report/report.shtml (accessed 21.03.14). 
Solecki, W.D., Rosenzweig, C., 2004. Biodiversity, biosphere reserves, and the big apple: a study of the New York Metropolitan Region. Ann. N. Y. Acad. Sci. 1023 105-124, http://dx.doi.org/10.1196/annals.1319.004.

Solecki, W., 2012. Moving toward urban sustainability: using lessons and legacies of the past. In: Zeman, F. (Ed.), Metropolitan Sustainability: Understanding and Improving the Urban Environment, vol. 34. Woodhead Publishing Series in Energy, Cambridge, UK, 776 pp.

Solecki, W., Leichenko, R., O’Brien, K., 2011. Climate change adaptation strategies and disaster risk reduction in cities: connections, contentions, and synergies. Curr. Opin. Environ. Sustain. 3, 135-141.

Taylor, K.E., Stouffer, R.J., Meehl, G.A., 2012. An overview of CMIP5 and the experiment design. Bull. Am. Meteorol. Soc. 93, 485-498.

The United Nations Office for Disaster Reduction. Available at: http://www. unisdr.org/we/campaign/cities (accessed 31.07.13).

United Nations Framework Convention on Climate Change. Available at: http:// unfccc.int/2860.php (accessed 31.07.13).

Wagner, M., Chhetri, N., Sturm, M., 2014. Adaptive capacity in light of Hurricane Sandy: the need for policy engagement. Appl. Geogr. 50, 15-23.

Walker, W.E., Haasnoot, M., Kwakkel, J.H., 2013. Adapt or perish: a review of planning approaches for adaptation under deep uncertainty. Sustainability 5 , 955-979.
Wise, R.M., et al., 2014. Reconceptualising adaptation to climate change as part of pathways of change and response. Glob. Environ. Change, http://dx.doi.org/ 10.1016/j.gloenvcha.2013.12.002.

Yohe, G., Leichenko, R., 2010. Chapter 2: Adopting a risk-based approach. Ann. N. Y. Acad. Sci. 1196, 29-40.

Zimmerman, R., Faris, C., 2010. Chapter 4: infrastructure impacts and adaptation challenges. Ann. N. Y. Acad. Sci. 1196, 63-86, http://dx.doi.org/10.1111/j.17496632.2009.05318.x.

\section{Useful Hurricane Sandy-Related Links}

Hurricane Sandy: One Year Later http://www.fema.gov/hurricane-sandyrecovery (accessed 21.03.14).

Programs for Business Recovery and Resilience. http://www.nycedc.com/ service/programs-business-recovery-resiliency (accessed 21.03.14).

Rebuild by Design: A Regional Analysis. http://www.rebuildbydesign.org/ research/ (accessed 21.03.14). 